\title{
Development of Bi Electrodeposition Process for Fabricating Microabsorber Array for High Sensitive X-ray Imaging Sensor
}

\author{
Hirotaka SATO, ${ }^{\text {a }}$ Hideomi KOBAYASHI, ${ }^{\text {a }}$ Hiroyuki KUDO, ${ }^{b}$ Toshimitsu IZUMI, ${ }^{b}$

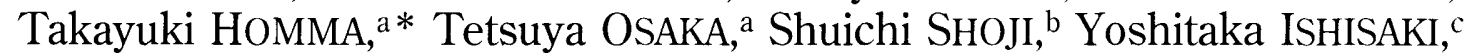 \\ Ryuichi FuJIMOTO, ${ }^{\mathrm{d}}$ and Kazuhisa MITSUDA ${ }^{\mathrm{d}}$
}

\author{
${ }^{a}$ Department of Applied Chemistry and ${ }^{b}$ Department of Electrical Engineering and Bioscience, Waseda University \\ (Okubo, Shinjuku, Tokyo 169-8555, Japan) \\ 'Department of Physics, Tokyo Metropolitan University (Minami-Osawa, Hachioji, Tokyo 192-0397, Japan) \\ ${ }^{d}$ High Energy Astrophysics Division, Institute of Space and Astronautical Science, Sagamihara (Kanagawa 229-8510, \\ Japan)
}

Received November 29, 2003 ; Accepted March 10, 2004

\begin{abstract}
Microscale $\mathrm{Bi}$ electrodeposition process was developed to fabricate the array of mushroom-shaped absorbers for the high sensitive X-ray imaging sensor, so called X-ray microcalorimeter array. The bath composition and operating conditions for Bi electrodeposition was optimized, and sufficient bath stability and surface smoothness of the deposits were achieved by applying the additives such as diethylenetriamine pentaacetic acid and sodium n-dodecyl sulfate with appropriate concentration. By applying the two-step exposure steps for the "stem" part and the "roof" part, the mold to deposit the mushroom-shaped microstructure was formed from single-layered photoresist coating. The absorber array was successfully fabricated by the sequential processes of Bi electrodeposition into the mold, precise polishing, and mold removal.
\end{abstract}

Key Words : Bi Electrodeposition, MEMS, Micromachining, X-ray Imaging

\section{Introduction}

In the lield of astronomy, X-ray spectroscopy has attracted much attention for exploring unknown high energy phenomena in the space, which requires precision tool for X-ray sensing. ${ }^{11}$ We have attempted to develop $\mathrm{X}$-ray micorocalorimeter, which is expected to be one of the most sensitive X-ray sensors, ${ }^{2}, 3$ ) by detecting the Xray photon energy from temperature rise of several $\mathrm{mK}$ caused by its incidence. The multi-pixel array of the Xray microcalorimeters can be applied to X-ray imaging sensor for next generation X-ray telescope system. ${ }^{2-5)}$

Figure 1 illustrates schematic design of single pixel of the X-ray microcalorimeter. It consists of an X-ray absorber, a temperature sensor, and a membrane, which acts as a thermal insulator. $\mathrm{A} \mathrm{Au} / \mathrm{Ti}$ bilayer with $\mathrm{Al}$ interconnects is used for the temperature sensor, which is called "transition edge sensor (TES)" since its electric re-

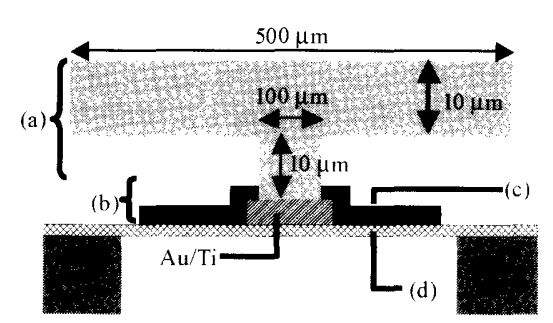

Fig. 1 Schematic design of single pixel of the X-ray microcalorimeter ; (a) X-ray absorber, (b) temperature sensor, (c) $\mathrm{Al}$ interconnects, and (d) membrane for thermal insulation. sistivity is extremely temperature-sensitive at the temperature around the superconducting transition edge and shows high energy resolution of several $\mathrm{eV} .{ }^{2, \ldots j}$ In order to minimize the "dead area" where the incident X-ray photons can not be reached to the TES part, the mushroom-shaped structure with $10 \mu \mathrm{m}$ thick roof part is formed onto each TES element. The absorber material is desired to have low specific heat in order to maximize the transfer rate of the heat from the top of the absorber to the TES part. At the operating temperature of X-ray microcalorimeter $(0.3 \mathrm{~K}), \mathrm{Sn}$ has low specific heat of 1.5 $\times 10^{-8} \mathrm{~J} \mathrm{~K}^{-1} \mathrm{~cm}^{-3}$ due to its superconducting state. Therefore, we have been investigating to fabricate the $\mathrm{X}$ ray microcalorimeter using $\mathrm{Sn}$ electrodeposition proc$\mathrm{ess}^{\left.2,{ }^{3}\right)}$ and the energy resolution of $136.5 \pm 3.5 \mathrm{eV}$ at 6 $\mathrm{keV}$ of X-ray photon was achieved. On the other hand, the Sn turns to be the superconducting state at the operating temperature, and under such a state, it is generally known that quasiparticle with relatively long lifetime is formed, which makes the energy resolution lower. Thus as an alternative approach, we attempt to apply the material which does not become superconducting state at the operating temperature, and focused upon $\mathrm{Bi}$ as a candidate, which has relatively low specific heat of $2.4 \times 10^{-i}$ $\mathrm{J} \mathrm{K} \mathrm{K}^{-1} \mathrm{~cm}^{-3}$ and does not become superconducting state at $0.3 \mathrm{~K}$. Application of $\mathrm{Bi}$ to the fabrication of the absorber for the X-ray microcalorimeter has been investigated using dry processes such as evaporation. ${ }^{6)}$ On the other hand, in the present work, we attempt to develop 
the microfabrication process of the absorber array for Xray microcalorimeter using $\mathrm{Bi}$ electrodeposition.

\section{Experimental}

We used $625 \mu \mathrm{m}$ thick n-type Si (100) substrates. whose surface was cleaned by dipping in methanol for 2 min, dichloromethane for $20 \mathrm{~min}$ and methanol for $2 \mathrm{~min}$ again to remove the residual contaminants. After drying by an oven at $135^{\circ} \mathrm{C}$ for $15 \mathrm{~min}$ and natural cooling, the "mold" for the mushroom-shaped microstructure array was formed by photolithographic technique. In this work, the positive photoresist of PMER P-LA 900 PM (Tokyo Ohka Kogyo), whose compositions are $40 \mathrm{wt} \%$ of novolak resin and $60 \mathrm{wt} \%$ of propylene glycol mono methyl ether acetate (PGMEA) and viscosity is $900 \mathrm{mPa}$, was used to form the mold. The $20 \mu \mathrm{m}$ thick photoresist coating was spin-coated on the substrate. Following the prebake at $110^{\circ} \mathrm{C}$ for $8 \mathrm{~min}$, ultraviolet light (UV) from mercury lamp $\left(65 \mathrm{~mW} \mathrm{~cm}^{-2}\right)$ was irradiated to the coating to form the mold pattern, whose details will be described later. After the exposure, the specimens were dipped in PMER developer (P-7 G, Tokyo Ohka Kogyo), which contains $3 \mathrm{wt} \%$ of tetra methyl ammonium hydroxide aqueous solution with $2 \mathrm{wt} \%$ of anion surfactant, for 3 $\mathrm{min}$ at the room temperature, followed by rinsing with deionaized water for $3 \mathrm{~min}$. A conductive seed layer of $100 \mathrm{~nm}$ thick Au on $20 \mathrm{~nm}$ thick $\mathrm{Cr}$ was formed on the mold by electron beam evaporation. Then $\mathrm{Bi}$ was electrodeposited into the mold up to $30 \mu \mathrm{m}$ thick using a potentiostat/galvanostat (Hokuto-Denko, HAB-151). Table 1 shows basic composition and operating conditions for the Bi electrodeposition, whose details will be described in the following section. After the deposition, the Bi layer surface was polished down to the designed thickness to form separate elements of the array using an automatic rotational polishing machine (Musashino Denshi, MA-200 $\mathrm{D}$, rotational speed : $110 \mathrm{rpm}$, load : $200 \mathrm{~g}$ ), using a nylon polishing cloth (Heraeus Kulzer, Orange) and polycrystalline diamond slurry (Engis, PC-S-4889, grain size : c.a. $1 \mu \mathrm{m})$. Finally, the photoresist mold was removed with acetone.

Following the procedure, the fabricated microstructures were observed by a scanning electron microscope (SEM, Hitachi, S-4700). Some specimens were treated by a focused ion beam milling (FIB, Hitachi, FB-2000 A) to observe the cross sectional regions under the roofs of the mushroom-shaped structures.

Table 1 Basic composition and operating conditions of $\mathrm{Bi}$ electrodeposition.

\begin{tabular}{ll}
\hline Chemicals & Concentration $/ \mathrm{g} \mathrm{t}^{-1}$ \\
\hline $\mathrm{Bi}_{2} \mathrm{O}_{3}$ & 20.3 \\
$\mathrm{HClO}_{4}$ & 54.7 \\
$\begin{array}{l}\text { Diethylenetoriamine } \\
\text { pentaacetic acid }\end{array}$ & $0-45$ \\
Sodium n-dodecyl sulfate & $0-500 \mathrm{ppm}$ \\
\hline $\begin{array}{l}\text { Current density } \\
\text { Bath temperature } \\
\text { pH }\end{array}$ & $25 \mathrm{~mA} \mathrm{~cm}^{-2}$ \\
\hline
\end{tabular}

\section{Results and Discussion}

The conditions of $\mathrm{Bi}$ electrodeposition were optimized prior to the fabrication of the mushroom-shaped absorbers. Figure 2 shows representative SEM images of the surface morphology of the deposited films from various bath compositions. Initially, the bath only containing $\mathrm{Bi}_{2} \mathrm{O}_{3}$ and $\mathrm{HClO}_{4}$ was used. However, the bath was quite unstable and formed precipitates immediately after the preparation. Moreover, the deposited film possessed dendritic feature, as is shown in Fig. 2(a). By adding diethylenetriamine pentaacetic acid (DTPA, $\left.\left[\left(\mathrm{HOOCCH}_{2}\right)_{2} \mathrm{NCH}_{2} \mathrm{CH}_{2}\right]_{2} \mathrm{NCH}_{2} \mathrm{COOH}\right)$, which is reported to stabilize $\mathrm{Bi}^{3+}$ in aqueous solution ${ }^{7}$ to the bath, it was confirmed that the formation of the precipitation was inhibited. However smooth surface was not obtained as is seen in Fig. 2(b). On the other hand, when sodium n-dodecyl sulfate (SDS, $\left.\mathrm{CH}_{3}\left(\mathrm{CH}_{2}\right)_{10} \mathrm{CH}_{2} \mathrm{OSO}_{3} \mathrm{Na}\right)$ was added to the bath together with the DTPA, flat and smooth surface was obtained (see Fig. 2(c)). After systematic survey, it was found that the optimum concentrations of DTPA and SDS were $45 \mathrm{~g}^{-1}$ and $500 \mathrm{ppm}$, respectively, which were employed for the following investigation. The $\mathrm{Bi}$ deposition rate is $560 \mathrm{~nm} \mathrm{~min}^{-1}$ at constant current density of $25 \mathrm{~mA} \mathrm{~cm}{ }^{-2}$, which is sufficient to fabricate the structure such as the mushroom-shaped absorber array with $20 \mu \mathrm{m}$ thick.

Next, we attempted to fabricate the mushroom-shaped absorber array using the procedure described above with the $\mathrm{Bi}$ electrodeposition. In our previous study, the molds for the stem part and the roof part were sequentially formed by two-step coating of the photoresist. " In order to simplify the process, we developed a new photolithographic technique with single resist coating, as is shown in Fig. 3. The exposure requires two-step UV irradiation ; first is for the stem part of the mushroom and second is for the roof. The roof parts were exposed mod-
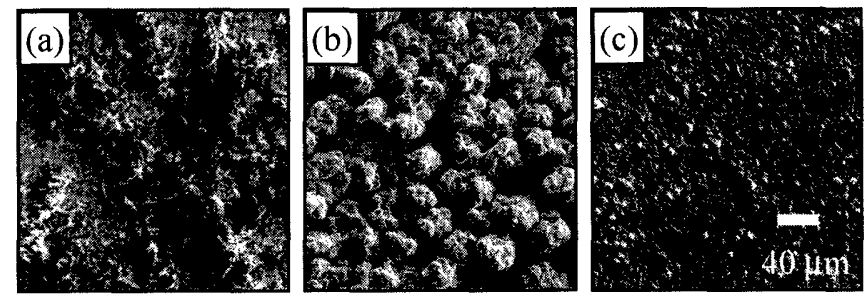

Fig. 2 Representative SEM images of the surface of films obtained from the $\mathrm{Bi}$ baths at $25 \mathrm{~mA} \mathrm{~cm}^{-2}$ for $15 \mathrm{~min}$ using additives ; (a) additive-free, (b) $45 \mathrm{~g} \mathrm{t}^{-1}$ of DTPA, and (c) coaddition of $45 \mathrm{~g}^{-1}$ of DTPA and $500 \mathrm{ppm}$ of SDS.

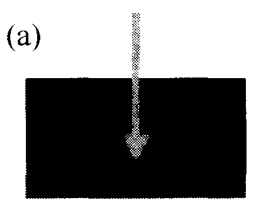

(b)
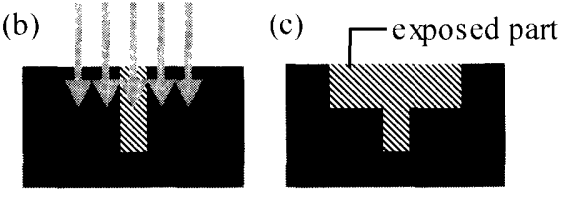

Fig. 3 The two step mold formation process for the mushroom-shaped microabsorber array; (a) UV irradiation for the stem part, (b) UV irradiation for the roof part, and (c) after the two steps of irradiations. 


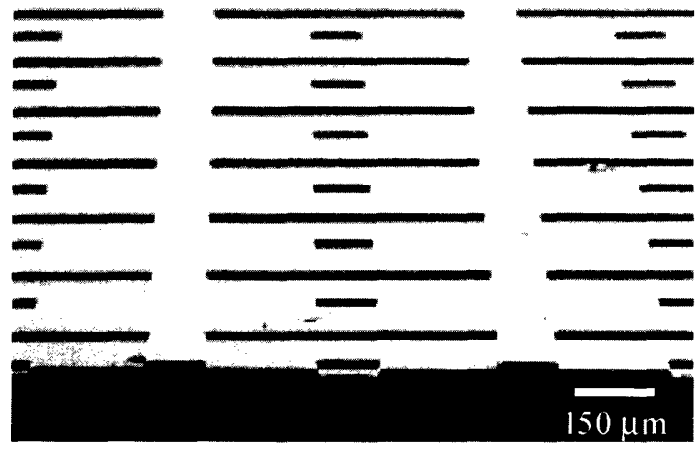

Fig. 4 SEM image of the bilayer mold for the mushroomshaped microabsorber array.

erately so that the exposed depth would be equal to the thickness of roof part and not reached to the bottom, as is schematically shown in Fig. 3(b). As a result of exposure optimization, it is clarified that UV irradiation steps of $400 \mathrm{~mJ} \mathrm{~cm} \mathrm{~cm}^{-2}$ for stem part and $315 \mathrm{~mJ} \mathrm{~cm}^{-2}$ for roof part are suitable conditions to form the fine mold as is shown in Fig. 4 of SEM image.

Figure 5 shows SEM image of the sample after the $\mathrm{Bi}$ electrodeposition, precise polishing, and acetone dipping. The array of uniformly formed mushroom-shaped microstructure can be observed in Fig. 5. We fabricated microscopic openings on some roof parts to observe the stem regions underneath them using the FIB and confirmed that there was no residual photoresist, clarifying that the free-standing mushroom-shaped absorber array was successfully fabricated by the $\mathrm{Bi}$ electrodeposition process. It is expected that the electrodeposition process can be applied to fabricate various three-dimensional, functional microstructures.

\section{Conclusion}

In the present work, $\mathrm{Bi}$ electrodeposition process for microfabrication of the mushroom-shaped absorber array for X-ray microcalorimeter was developed. In order to improve the bath stability and surface morphology of the deposition film, the conditions of $\mathrm{Bi}$ electrodeposition were optimized. As a result, applying DTPA and SDS to the bath was found to prevent precipitation and smooth the surface. In fabrication process of the absorber, the bilayer mold for the mushroom could be formed by controlling UV irradiation region and exposed depth with single-layered photoresist coating in photolithographic technique. Then, $\mathrm{Bi}$ was filled into the mold by the $\mathrm{Bi}$ electrodeposition. Following surface polishing and photoresist removal with acetone, it is confirmed that the designed $\mathrm{Bi}$ absorber array was successfully fabricated. It is

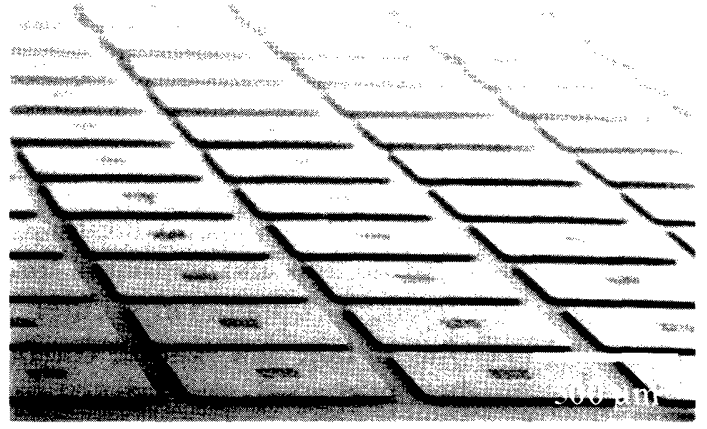

Fig. 5 SEM image of the mushroom-shaped microabsorber array fabricated by the $\mathrm{Bi}$ electrodeposition process.

expected that the electrodeposition processes are widely applied to fabricate various three-dimensional nano- and microstructures for functional microsystems.

\section{Acknowledgements}

This work was financially supported in part by the Research Grant from the Shorai-Foundation and performed at the 21st Century Center of Excellence (COE) Program "Practical Nano-Chemistry" from The Ministry of Education, Culture, Sports, Science and Technology, Japan.

\section{References}

1) P. Lechner, R. Hartmann, P. Holl, G. Lutz, N. Meidinger, R. H. Richter, H. Soltau, and L. Struder, Nucl. Instrum. Methods in Phys. Res. Sect. A, 509, 302 (20).3).

2) T. Arakawa, H. Kudo, H. Sato, H. Kobayashi, T. Izumi, S. Ohtsuka, K. Mori, S. Shoji, T. Osaka, T. Homma, K. Mitsuda, N. Yamasaki, R. Fujimoto, N. Iyomoto, T. Oshima, K. Futamoto, Y. Takei, T. Ichitsubo, T. Fujimori, K. Yoshida, Y. Ishisaki, U. Morita, T. Koga, K. Shinozaki, K. Sato, N. Takai, T. Ohashi, Y. Kuroda, M. Onishi, M. Goto, and F. Beppu, Proc. 10th Int. Workshop on Low Temperature Detectors, in press.

3) T. Homma, H. Sato, H. Kobayashi, T. Arakawa, H. Kudo, T. Osaka, S. Shoji, Y.Ishisaki, T. Oshima, I. Iyomoto, R. Fujimoto, and K. Mitsuda, J. Electroanalytical Chem., 559, 143 (2003).

4) D. A. Wollman, K. D. Irwin, G. C. Hilton, L. L. Dulcie, D. E. Newbury, and J. M. Martinis, J. Micros., 188, 196 (1997).

5) J. van der Kuur, P. A. J. de Korte, H. F. C. Hoevers, W. M. B. Tiest, N. H. R. Baars, M. L. Ridder, E. Krouwer, M. P. Bruijn, M. Kiviranta, and H. Seppa, IEEE Trans. Appl. Supercond., 13, 638 (2003).

6) K. Pretzl, Nucl. Instrum. Methods in Phys. Res. Sect. A, 454, $114(2000)$.

7) Y. N. Sadana, R. N. Gedye, and S. Ali, Surf. Coating Tech., 27, 151 (1986). 